\title{
EL TEATRO VARGASLLOSIANO DE LOS OCHENTA: LA MUJER ENTRE LA TINTA Y LA SANGRE
}

\author{
Elena Guichot Muñoz \\ Universidad de Sevilla \\ eleguichot@gmail.com
}

\section{RESUMEN / ABSTRACT}

El retrato femenino en la obra de Mario Vargas Llosa se ha juzgado de forma unánime por la crítica como carente de hondura psicológica y su estudio ha polarizado los personajes femeninos entre los esquemas literarios de la prostituta y la virgen. En la década de los ochenta predomina paulatinamente la presencia de la mujer en la literatura vargasllosiana, tal y como vemos en el ensayo La orgía perpetua, en el que descubrimos el enamoramiento del autor por la heroína Emma Bovary, en la novela La tía Julia y el escribidor, donde la heroína será su amada y sobre todo en la trilogía teatral: La señorita de Tacna, Kathie y el hipopótamo y La Chunga. Analizando en detalle la poética femenina en estas piezas, y sus paralelos con la narrativa, se revelan concomitancias entre el dibujo de la mujer y la significación de la literatura para Mario Vargas Llosa que desembocarán en una correspondencia iluminadora.

Palabras clave: La Chunga, Kathie, La señorita de Tacna, mujer, Vargas Llosa.

The portrayal of women in the work of Mario Vargas Llosa was unanimously judged by critics as lacking psychological depth. Moreover, research has located these female characters between the literary schemes of prostitute and virgin. During the eighties the presence of women in Vargas Llosa's literature grows more predominant in the light of the essay "The Perpetual Orgy", in which the author's infatuation for the heroine Emma Bovary is evident, in the novel Aunt Julia and the Scriptwriter, where the heroine is his sweetheart, and especially in the theatrical trilogy, The Young Lady de Tacna, Kathie and the Hippopotamus, and La Chunga. An in-depth analysis of both the female poetics in these pieces and its parallels within the narrative reveal similarities between the image of woman and the significance of literature for Mario Vargas Llosa that will lead to enlightening correspondences.

KEY WORDS: La Chunga, Kathie, The young lady from Tacna, women, Vargas Llosa. 
"No se trata de un mundo histórico-social sino de un mundo soñado. Las cosas ocurren en él por una necesidad inmanente... y, en el tiempo que duran, se hallan liberadas por entero de ataduras con otro contexto que no sea la propia voluntad... de los protagonistas" (Bataille, Historia del ojo 14). Esta cita, extraída del prólogo de Vargas Llosa a Historia del ojo (1928), podría ser una definición de gran parte de la producción teatral del reciente Premio Nobel, ya que los "demonios" vargasllosianos - entendidos como la propia voluntad, el instinto del creador, el deseo insatisfecho del individuo-se quitan la máscara de la narrativa para mostrarse en carne y hueso sobre las tablas. La imaginación, el universo de la fantasía cobra una importancia radical a finales de los setenta, contexto crítico del escritor peruano que cuestiona entonces sus modelos literarios y culturales en un sinfín de artículos periodísticos y obras ensayísticas que dan huella de su recorrido intelectual ${ }^{1}$; sin embargo es el teatro el género escogido por el autor para mostrar sin pudor los retales de la obsesión primigenia, aquella que no se desembaraza nunca de la figura del escritor. En los años ochenta sorprende al público con La señorita de Tacna (1981), Kathie y el hipopótamo (1983) y La Chunga (1986), tres obras que componen una trilogía metadramática en toda regla, y que comparten asimismo una alumbradora coincidencia que será el nudo gordiano de este artículo: el protagonismo de la mujer. Analizaremos minuciosamente la significación de la presencia femenina en cada una de las piezas teatrales de los ochenta, ya que esta se convierte en el centro sobre el que bascula toda la intriga, exigiéndonos por tanto ir más allá del mero análisis caracterológico, y conduciéndonos a una interpretación metaliteraria que sitúa al personaje escénico entre la efímera carnalidad y la inmanencia de la tinta. Para ello, ha de valorarse también el análisis crítico de la mujer en la narrativa, al considerar que existe una continuidad total en la obra vargasllosiana.

La relevancia de esta aparición en la década de los ochenta salta a la vista al posar los ojos en los títulos de las novelas del autor peruano desde el inicio de su carrera literaria. Haciendo una somera recapitulación, observamos cómo en una primera etapa el contexto situacional reclama una atención principal en el rótulo, con los ejemplos de La ciudad y los perros (1963), La casa verde (1965) y Conversación en la Catedral (1969); el autor continúa

${ }^{1}$ Un claro ejemplo de este posicionamiento se refleja en los artículos reunidos bajo el nombre de "Entre Sartre y Camus" que se encuentran en el primer volumen de Contra viento y marea (1962-1982), que tal y como su nombre indica, analiza la discusión dialéctica entre estos dos autores canónicos: Jean Paul Sartre y Albert Camus. 
en una segunda etapa - donde da cabida a la subliteratura- en la que los personajes dispuestos en pares ocupan la cubierta del libro: Pantaleón y las visitadoras (1973) y La tía Julia y el escribidor (1977). Pero en la década de los ochenta incurre en la repetición no azarosa de tres nombres de mujer que se convierten así en protagonistas de su estreno en el teatro: la señorita de Tacna, Kathie y la Chunga.

No es ninguna novedad el reproche de la crítica ante la presencia de papeles femeninos maniqueos o ciertamente planos en la novelística de Vargas Llosa. Los analistas de su obra-si exceptuamos su última etapa literaria-tienen un juicio unánime a la hora de clasificar a la mujer en su literatura inicial, que no supera la "dualidad sin transiciones entre los extremos de madre o prostituta, mujer buena/mala, esposa de adentro/"polilla' de afuera que corroe" (Boldori 36-37). No hay más que observar los personajes femeninos que aparecen en La ciudad y los perros, para ceder un catálogo que se repetirá al menos en las novelas de la década posterior: la figura de Pies Dorados, prostituta, objeto de deseo del mundo varonil de la escuela militar; las madres de los cadetes, maltratadas y abandonadas por sus maridos; y la diana de los enamoramientos: Teresa. Giulia De Sarlo, en su artículo titulado "Entre lo femenino y lo masculino: la narrativa de Vargas Llosa a la vuelta del milenio" aclara con rotundidad la siguiente evidencia: "Nunca se describe a Teresa en sí, sino siempre a través de los ojos de quien la busca, de quien la quiere: como la dama de una novela de caballería, pero distorsionada por una modernidad cruel, Teresa mueve la acción de Arana, Alberto y el Jaguar, pero no elige, no participa, no actúa" (9). Asimismo, es iluminador el ejercicio de síntesis que realiza el dramaturgo peruano Alonso Alegría para poner en escena Los cachorros, donde el personaje principal femenino vuelve a ser Teresita. Los personajes corales, una pandilla de cuatro amigos, llevan a escena los roles de la novela ciñéndose a la misma estructura anticonvencional -el vaivén pasado y presente; la presencia del "yo", "nosotros", "ellos"- con una significativa salvedad: la caracterización de Teresita siempre la realiza la misma actriz y el director la define de la siguiente forma en las didascalias:

Teresita Arrartre es un recuerdo colectivo que se materializa. Como recuerdo es irrealizado, casi irreal. No resultaría incongruo que Teresita apareciera desnuda o vestida de una forma totalmente fantástica: ellos la recuerdan como quisieran haberla visto. Es importante que la misma actriz haga no solo de enamorada sino también de la madre de Cuéllar y de la puta final de la pieza (Polo 129). 
Percibimos en su obra una mujer que no es de carne y hueso; un elemento irreal, un "demonio" añadido que actúa como diana de las fantasías de los protagonistas masculinos. Las perversidades a las que se enfrentan los personajes varoniles ante las estructuras asfixiantes de la vejatoria escuela militar, de Piura y la desolación del desierto, del venenoso estrato de la corrupción política... tienen como vía escapatoria la presencia de personajes como La Musa, Lalita, Bonifacia, Amalia, Queta, y un largo etcétera de mujeres que figuran como objeto de la dominación masculina.

No obstante, a pesar de su polarización caracterológica, la mujer se va consolidando a lo largo de la evolución literaria de Mario Vargas Llosa como una fuente primordial para examinar el proceso creativo del novelista. $\mathrm{Al}$ analizar el protagonismo femenino a lo largo de su trayectoria literaria, percibimos que el retrato dicotómico que ejerce el autor arequipeño sobre la figura literaria de la mujer no responde a un simple desconocimiento de su psicología, sino más bien a una estrategia discursiva que puede seguirse a lo largo de toda su obra. Para entender este proceder es necesario analizar el artículo de Elvire Gómez Vidal, que desentraña con lucidez la poética de esta compleja imagen a través del análisis de un personaje fundamental en una de sus obras cumbre: La Musa. La amante de Cayo Bermúdez es el enigma que infunde en Santiago y Ambrosio un estado perenne de desasosiego, y ella, subrepticiamente, los convoca en el centro sagrado, el bar la Catedral: "A cada desciframiento logrado del enigma propuesto, a cada reconocimiento de la diosa Musa en la pobre cantante Hortensia 'la Musa', las fuerzas del mal retrocederán, el milagro se producirá, el alumbramiento se llevará a cabo: la Musa, cual Fénix, volverá a nacer de sus cenizas, es decir, del relato de su muerte" (Gómez 297). Los dos testigos y actores del aniquilamiento, del siniestro destino del Perú en manos de la corrupción dictatorial, se culpabilizan del asesinato de La Musa -"Te mataron los mismos de nuevo Musa, o esta segunda vez ¿te mató todo el Perú?" (Cit. en Gómez 295)- y no será casual el apelativo de la cantante, ya que como afirma la crítica, "representa el asesinato de la creación poética y también el de la historia y el de la memoria, crimen cometido por Perú entero" (295). La Musa evidencia la función de la ficción, relato de la destrucción, de la "lenta, inexorable inmersión en la mugre invisible" (Vargas, Conversación 50) que sufren las víctimas de esta sociedad infecta.

Como mencionamos anteriormente, el dibujo del híbrido mosaico de historias anega las novelas inaugurales de Vargas Llosa dejando en un segundo plano cuestiones que serán el motor principal de su obra posterior, ya que como recuerda Jorge Edwards: 
Mario, súbitamente provocado, manifestaba su fervorosa preferencia por Tolstoi, el Tolstoi de Guerra y paz, sobre todo, y decía que el autor de los endemoniados, con sus complicaciones psicológicas, su permanente exposición de una subjetividad atormentada, su énfasis puesto siempre en la interioridad, en desmedro de la acción y de la historia, no le interesaba (50).

Su interés por el ámbito metaliterario va desarrollándose al mismo tiempo que aumenta la importancia del papel femenino, y la novela que ejemplifica este paralelismo con mayor precisión es sin lugar a dudas La tía Julia y el escribidor (1977). La novela destaca por su entrada a la cultura de masas a través de la inserción de los radioteatros de Pedro Camacho, y por la introducción del humor que, aunque ya tuvo su precedente en Pantaleón, posee en esta especie de serial una importancia estructural que aleja definitivamente al narrador de la gravedad y el compromiso social de las primeras novelas. Mucho se ha discurrido sobre la importancia de la figura del escribidor Pedro Camacho en confrontación con el intelectualismo de Varguitas, dicotomía que se disuelve una y otra vez a lo largo de la lectura. Sin embargo, no se ha apreciado con la misma atención la figura de la tía Julia, protagonista femenina que participa en el juego literario como una lectora crítica más de su amante. José Morales Saravia, aludiendo a la colisión entre el incipiente escritor Varguitas y el escribidor Pedro Camacho, refiere un pasaje de la novela en que Varguitas recrimina a la tía Julia sus lecturas huachafas -categorías del mal gusto y de la cursilería en el Perú-y le explica la censura que deben ejercer los escritores frente a lo "huacho" (56). La respuesta de Julia deja perplejo al joven autor: "La tía Julia me dio una estocada mortal diciéndome que el cuento había salido melodramático y que algunas palabritas, como trémula y sollozante, le habían sonado huachafas" (Cit. en Morales 57). Lo huachafo, definido por el autor como "urbana, irracionalista y sentimental" (Vargas, Diccionario 199) no es para Vargas Llosa una categoría desagradable pues reivindica esta estética como parte de la psicología y la cultura de Perú. En un artículo-homenaje a este estilo aclara que no debe confundirse este modelo con la cursilería ya que "La huachafería no pervierte ningún modelo porque es un modelo en sí misma; no desnaturaliza patrones estéticos sino, más bien, los implanta, y es, no la réplica ridícula de la elegancia y el refinamiento, sino una forma propia y distinta - peruana- de ser refinado y elegante" (Vargas, Diccionario 199). Su antecedente al defender los rasgos melodramáticos, la violencia, la truculencia y el exceso - ajenos a la literatura canónica u oficial, pero con una fijación en lo real inapelable- se encuentra en la obra ensayística La orgía 
perpetua (1975), donde Vargas Llosa analiza la novela Madame Bovary tal y como si se tratase de una auténtica exposición de sus gustos literarios, encarnados en la heroína de Flaubert. En la historia de amor con la tía Julia vemos una recuperación del género folletinesco y de la novela rosa que, aun siendo parodiados y sometidos a una elaboración formal anticonvencional, cobran una relevancia protagonista, y son indudablemente refrendados por la amada de Varguitas. Marina Gálvez extrae una conclusión alumbradora sobre la relación entre las dos heroínas de Vargas Llosa, que nos conduce al punto de confluencia entre estos dos libros -la novela y el ensayo- que poseen tanto de autobiográfico:

La creación de un personaje como Julia, que recuerda a Mme. Bovary por su rebeldía como recordaría a la Regenta; "la rebeldía -dice Vargas Llosa- en el caso de Emma no tiene el semblante ético que en los héroes viriles de la novela decimonónica, pero no es menos heroica; se trata de una rebeldía individual y, en apariencia egoísta; ella violenta los códigos del medio azuzada por problemas estrictamente suyos, no en nombre de la humanidad, de cierta ética o ideología, es porque su fantasía y su cuerpo, sus sueños y sus apetitos se sienten aberrojados por la sociedad" (Polo 124).

La tía Julia es la encarnación de esa rebeldía ciega, que violenta los códigos familiares para cumplir su propia voluntad, aquella que se adapta a la altura de sus fantasías melodramáticas, pero también lo será entonces la literatura vargasllosiana que, cansada de rendir cuentas a los códigos estéticos imperantes de la literatura canónica, rompe con el corsé intelectualista para abrirse a un "espacio de la recepción visceral" (Barchino 228). El mundo de la ilusión se introduce en su obra y se encara a la realidad objetiva ya que, en palabras del autor: "la realidad descubre su sordidez por contraste con la imagen embellecida que trata de ella" (Vargas, Orgía 136), y la mujer será la encarnación de ese paraíso, de ese misterio que constituye la vocación literaria, escurridiza e inaprensible, persuasiva y seductora. La tía Julia trastoca la realidad cotidiana de Varguitas -como lo hará la "niña mala" con Ricardo Somocurcio treinta años después- al mismo tiempo que el escritor intenta buscar una literatura ceñida a la realidad. Precisamente en 1977 Mario Vargas Llosa realiza unas declaraciones sobre su reciente novela que evidencian la coyuntura crítica que está viviendo el autor y su rechazo al realismo como estética hegemónica: "He comprobado o vuelto a comprobar lo que siempre supe o al menos siempre sospeché: que el realismo no existe. Lo único que existe es una ficción del realismo" (Vargas, Entrevistas 113). 
Podemos afirmar, en palabras de Elvire Gómez Vidal, que el autor "entrelaza una preocupación 'realista' y un cuestionamiento metatextual, entrelazamiento cuyo factor desencadenante es precisamente la figura femenina" (285). Con esto no estamos justificando que haya un mayor desarrollo de la subjetividad femenina en la literatura vargasllosiana, pero sí es posible desentrañar el papel de la mujer en la narrativa de Vargas Llosa desde "su naturaleza de ser de tinta y de papel, de vivant sans entrailles" (285), y nuestra labor a partir de ahora será la de desenmascarar a este personaje de tinta y papel en las obras dramáticas de los años ochenta, alto en el camino metaliterario del autor arequipeño.

La señorita de Tacna cuenta el proceso de formación de una novela: Belisario, incipiente escritor, decide contar la "historia de amor" de Mamaé, su tía abuela que, tras vivir el desengaño amoroso por su prometido en los años veinte, se queda soltera toda la vida al cuidado de sus sobrinos, con una vida austera y consagrada a la religiosidad y a la aceptación rígida de las normas sociales. Mamaé, al otro lado del escenario, muda de época y varía entre la primera, segunda y tercera persona, dependiendo de los caprichos de su memoria: se comporta ya como una mujer de cien años de edad delirante, ya como la soñadora y joven Elvira, o bien como la abnegada Mamaé que cuida de los hijos de sus primos, o la señorita de Tacna que cuenta cuentos a su sobrinito.

Al igual que la tía Julia, que tiene por pareja a su escribidor Varguitas, cada una de las protagonistas de estas piezas tendrán sus pares; en este caso, Belisario posará sus ojos sobre la figura de Mamaé para descubrir o inventar en ella sus más recónditos secretos. Esta dualidad no es cerrada y escindida, sino que posee un espacio común que recorre el camino de la identidad a la alteridad, y viceversa, en un juego especular que desarrolla el tema de la creación literaria desde su vertiente más subjetiva. El nivel "metadiegético" de los sueños, los anhelos, las frustraciones de Mamaé y de Belisario se intercala con otro nivel que correspondería a la "realidad objetiva" -según la terminología vargasllosiana. No obstante, estos niveles se entrecruzan y se confunden una y otra vez con el propósito de mostrar la veleidosa condición humana: "la objetividad y la subjetividad conjugadas o, más bien, conjugándose" (Vargas, Teatro 258). El autor pretende poner sobre el escenario el desdoblamiento que realiza el ser humano cada vez que ejercita la imaginación, y elige el teatro puesto que, en palabras del autor, es "un género privilegiado para representar el inquietante laberinto de ángeles, demonios y maravillas que es la morada de nuestros deseos" (259). 
Lo curioso de la entrada de Vargas Llosa en la categoría teatral es que siendo el género mimético por excelencia el género que prima la acción por encima de todo, en la trilogía metadramática nos encontramos según la valoración de José Monleón "un no-teatro, planteado a través de una estructura formalmente teatral" (Vargas, Semana 95). La cotidianeidad de los temas: los celos, el amor, el honor, los tabúes de la sociedad, etc., se insertan en una estructura que desacomoda al espectador en con un código temporal y espacial antojadizo que pasa de los años 20 a los años $80^{2}$, de Tacna a Lima, en un abrir y cerrar de ojos. Además, los personajes, extraídos de la propia biografía del autor ${ }^{3}$, son ciertamente maniqueos: las figuras femeninas son un simulacro, una ficción, irreales, plagadas de estereotipos literarios que podrían encajarse en una novelita de Flaubert o en un melodrama de Corín Tellado; mujeres "buenas", y mujeres "malas" pueblan la escena discurriendo en la mente de Mamaé. Si nos quedamos con una visión superficial de la obra, podríamos deducir que se trata de un juego literario alejado de una intención realista. Sin embargo, leyendo los prólogos que realiza el propio autor a su teatro, descubrimos que el verdadero objetivo de Vargas Llosa es precisamente el de dibujar la sutil frontera entre la ficción y la realidad, a través de unos actores de carne y hueso:

Ningún género manifiesta tan espléndidamente la dudosa naturaleza del arte como una representación teatral. A diferencia de los personajes de una novela o un cuadro, los del escenario son de carne y hueso y viven ante nuestros ojos los roles que protagonizan. Los vemos sufrir, gozar, enfurecerse, reír. Si el espectáculo está logrado, esas voces, movimientos, sentimientos, nos convencen profundamente de su realidad. Y, en efecto, ¿qué hay de ellos que no se confunda con la vida? Nada, salvo que son simulacro, ficción, teatro (Vargas, Teatro 132).

Existe un denominador común entre las fantasías de Mamaé que Belisario decide rescatar: todas ellas son movidas por la voluntad, por esa "morada de los deseos", que aun habiendo sido aplacados, se liberan indiscriminadamente a sus cien años; "el deseo, como el agua, seguirá surcando el cuerpo de la

2 Véase Óscar Rivera Rodas, "El código temporal en La señorita de Tacna", Latin American Theatre Review, 19.2, 1986. 5-16.

3 Véase Oviedo, José Miguel, De la tía Julia a La señorita de Tacna", Quimera 4 (1981): 23-26. 
recatada Elvira y se transformará en contenido latente en los sueños y la imaginación de Mamaé" (Rojas 151).

Belisario es el encargado de desatar en su relato las emociones contenidas de la psiquis de Mamaé. Cabe ejemplificar este proceso liberatorio con una escena en que su aparente virginidad espiritual se destruye. Belisario -o el álter ego de Vargas Llosa- suelta por fin a la señorita de los amarres de una opresión sexual que se ejerce en el ámbito de lo público y de lo privado, de lo real objetivo y de lo imaginario: "MAMAÉ: De repente la señorita empezó a sentir otra cosa. Peor que el vértigo. Le temblaba el cuerpo y tuvo que sentarse en la bañera" (Vargas, Teatro 115). Mamaé cuenta en tercera persona cómo se excitó leyendo la carta que Pedro, el marido de su prima Carmen, le escribía a su esposa contándole una infidelidad con una india de Camaná. Mamaé traduce el acto sexual -que se escenifica en otra parte del escenario- por una paliza que le infringe el "caballero" Pedro por el "mal" comportamiento de la india. De nuevo la polarización buena/mala actúa en la mente de Mamaé para ocultarse a sí misma una realidad que le parecía insoportable, no por la falta ética del esposo, sino porque ella "demudada" sentía que recibía esos golpes, y se deleitaba con ello (116). La relación entre el placer y el dolor tiene un paralelismo clave con la relación Eros-Tanatos. La crítica Rojas Benavente utiliza las teorías de Julia Kristeva para dar explicación a las transmutaciones que se dan continuamente en la obra entre Mamaé y sus "supuestos" polos opuestos; "la señora Carlota", mujer con la que su prometido la engañó, y la "india mala": "De acuerdo a Julia Kristeva: 'Por la censura, la conciencia transforma el deseo refrenado en remordimiento y en culpabilidad, pero también en autodestrucción, la agresividad toma al yo como punto de mira en el masoquismo o en la melancolía" (Cit. en Rojas 153). Esto aclararía la "paliza" en que la señorita traduce el encuentro amoroso citado. El deseo es entonces el motor que da vida a esta mujer de cien años, que manipula sus recuerdos para paliar su realidad inminente: una muerte o un abandono en un asilo:

Joaquín ha cogido las manos de la Mamaé; las besa, apasionadamente. JOAQUín: Pero, más todavía que tus manos me gusta de ti otra cosa, Carlota.

MAMAÉ: (Con miedo) ¿Qué cosa? ¿Qué es lo que más te gustaba de esa mujer?

AGUSTÍN: O sea, metemos a la Mamaé al Asilo y todo resuelto. Claro, es muy fácil. Porque ustedes piensan en el Asilo privado de San Isidro donde estuvo la tía Augusta. Desde luego que allí no 
sufriría. Es tan limpio, con enfermeras que cuidan a los viejitos día y noche y los sacan a pasear a los jardines. Hasta les dan cine una vez por semana ¿no es cierto? (Con sarcasmo) ¿Saben ustedes la fortuna que cuesta ese lugar?

JOAQUÍN: Tu cuello. Deja que lo bese, que sienta su olor. Así, así. Ahora quiero besarte en las orejas, meter mi lengua en esos niditos tibios, mordisquear esas puntitas rosadas Por eso te quiero, soldadera. Sabes darme placer. No eres como Elvira, una muñequita sin sangre, una boba que cree que el amor consiste en leer los versos de un bobo que se llama Federico Barreto (67-68).

Federico Barreto será otra de las materializaciones de su deseo, poeta tacneño que le escribe un poema de adoración amorosa que deja escrito en un abanico, en medio de la confusión de un baile de máscaras. Este abanico impregnado de deseo frustrado: "No abrigues pues, temor porque te alabo: Ya que no puedo, Elvira, ser tu dueño, déjame, por lo menos, ser tu esclavo", acompaña a Mamaé hasta el día de su muerte en el que recita en alto los últimos versos del poeta.

La crítica María Elvira Luna Escudero Alie trata el espacio de carnaval en el baile de Mamaé bajo referencias bajtinianas: "En ese espacio-tiempo carnavalesco del que habla Bajtin, se anulan las categorías sociales, y también la identidad personal, el tiempo no existe; se detiene, es un tiempo de excepción, un paréntesis en el transcurrir (lineal) del tiempo" (88). El bardo tacneño existió en la realidad y forma parte del cancionero popular peruano, pero lo más llamativo es que en esta pieza aparece como "uno de los esclavos de la hacienda Moquegua" o un "mandingo cimarrón" (Teatro 38-39) y Mamaé al descubrirlo se vuelve contra él: (Petrificada de espanto.) ¡Un negro! ¡Un negro! ¡La mascarita era un negro! ¡Ayyy! ¡Ayyy! ¡Ayyy!” (Teatro 37). Significativo paralelismo se sucede tras esta escena, ya que el negro cimarrón recibirá una paliza similar a la que recibe la india. José Miguel Oviedo advierte que "El placer por delegación es seguido por un castigo también vicario" (25), y la señorita, impulsada por su remordimiento, acudirá cada domingo al lugar donde él vive, que precisamente es el nido de amor donde su prometido Joaquín se encontraba con su amante.

Pero, “¿Por qué impulso masoquista Elvira regresa cada domingo a ese antro de perdición, participa en la misa en la que los negros cantan y bailan y revive como una voyeuse la escena de pasión loca entre su novio y la amante Carlota?"(Gómez 153). George Bataille decía en su libro El erotismo que "la sensualidad es en principio el terreno de la irrisión y de la impostura, tiene como esencia ser un gusto por perder el pie pero sin hundirse", y añade, 
"esto no puede hacerse sin un engaño del que somos a la vez autores ciegos y víctimas" (249); el erotismo, terreno limitado por diversas prohibiciones ejercidas a lo largo de la historia, y por ende, de la transgresión de dichas leyes, revela los secretos más ocultos del ser humano. Y Mamaé, simbólicamente, morirá escuchando los versos que le regaló el poeta, transgrediendo su rígida ética en su imaginación paliativa.

"Dos cosas son inevitables: no podemos evitar morir, y no podemos evitar tampoco 'salir de los límites'. Morir y salir de los límites son una misma cosa" (Bataille, El erotismo 146); paralelamente observamos el deseo de Belisario; el escritor, en el Perú de los años en que Vargas Llosa comienza a escribir, realiza un acto de rebelión ante las fuerzas sociales; existe un "rechazo de la vocación literaria por una sociedad que no la aprueba como 'ocupación viril', que no le reconoce un lugar de prestigio entre sus prioridades, es uno de los demonios histórico-culturales que hostigan al escritor [...] habrá de asociarse en el espíritu del creador con vagas y oscuras sensaciones culposas" (Boldori 30).

Belisario huye de los comentarios de sus tíos que se mofan de él por querer tomar el oficio de poeta. Pero también logra escaparse asimismo de la autocensura que le impedía escribir meras "historias de amor":

BELISARIO:... ¿Para qué quieres escribir una historia de amor? ¿Para tener esa miserable compensación que no compensa nada? ¿Para eso, para pasar una vez más por las horcas caudinas, Belisario? ¡Sí, por eso! ¡Maldita aguafiestas, largo de aquí! ¡Abajo la conciencia crítica!... Solo sirve para estreñirte, castrarte, frustrarte (24).

En esta década su preocupación temática discurre por el mundo de la sinrazón, del inconsciente "que a veces esclaviza la conciencia" (Vargas, Contra 263). Excede los límites de la "conciencia crítica" transgrediendo de nuevo la literatura, introduciendo los componentes subliterarios - melodrama, violencia, truculencia, color local- pero manejándolos en una estructura dispar: el drama dentro del drama, virando de este modo la atención hacia el juego teatral, hacia el destape de la fabricación de una historia, de la historia de una mujer que compuso su vida de tinta y papel, y que, no casualmente, ejerció en la vida real del autor como narradora de sus primeros cuentos. Mamaé será el primer eslabón en la rúbrica de lectores y creadores de ficciones que componen la familia Llosa, entre los que también están el propio Belisario, bisabuelo del autor, y escritor de una novela, y el abuelo Pedro, escritor de versos. Alonso Cueto le interroga en una entrevista sobre una de sus pesadillas o sueños recurrentes, a lo que Mario Vargas Llosa responde: 
Desde hace algunos años sueño mucho con Mamaé. Es un personaje que se me aparece con frecuencia. No me acuerdo que hablemos pero la veo sentada en su silloncito ahí en la ventana o caminando o apoyándose en una silla, tenía una silla como un bastón. Esa silla la veo en sueños. Se trata de un sueño más bien nostálgico porque es un personaje muy entrañable de mi infancia, de mi juventud, y como un símbolo de la familia también. Era lo permanente (Cueto 76. La cursiva es mía).

La voz de la narradora vuelve a surgir en la siguiente pieza de teatro: Kathie y el hipopótamo. Una burguesa adinerada se divierte durante dos horas al día relatando de forma divertida sus viajes exóticos por Asia y África, mientras Santiago, fiel amanuense, transcribe con recursos literarios manidos la oralidad espontánea. En un segundo nivel "metadiegético" aparecen las imaginaciones de estos personajes que, bien corrigen su pasado, bien fantasean situaciones dramáticas excesivas, confundiendo finalmente al espectador en un sinfín de historias que forman una inmensa "caja china" sobre el escenario.

De nuevo, una pareja sube a escena: Santiago Zavala, personaje ya protagonista de Conversación en la Catedral, conformado con su destino mediocre, finge tras una apariencia de intelectual de la que él mismo se burla; y Kathie Kennety, mujer socialmente bien situada que pretende acabar con su monotonía vital y su ignorancia cultural a través de la colaboración de Santiago, pero que vuela en su imaginación con las "tragedias griegas" amorosas que quiso o quiere protagonizar.

En esta obra es más complicado aún discernir entre aquello que es "realidad objetiva" y aquello que pertenece al mundo de la imaginación, por lo que finalmente desconocemos la "biografía" real de los personajes; no obstante, lo que sí se puede confirmar en una simple lectura es que el motor que mueve las fantasías de los dos personajes vuelve a ser la oscura "morada de los deseos". Siguiendo la estela de Zavalita, aparece el personaje literario de Ana, que Ellen Watnicki define como "la protagonista de cine mexicano" (407). La postura de inferioridad que adquiere en la novela desaparece en esta pieza, en la que Ana le recrimina haberle engañado respecto a sus teorías socialistas aplicadas al matrimonio: "Yo te di gusto. Hice todo lo que me pediste para que existiera el amor-solidaridad. ¿Lo hice o no lo hice? ¿No dejé mi trabajo en la boutique? ¿No me puse a estudiar sociología, como me aconsejaste...?" (Teatro 179). Esta escena imaginaria bien podría ser un recuerdo del pasado, bien podría tratarse de los remordimientos o deseos frustrados de Santiago, que nunca estuvo convencido de su matrimonio y 
ahora flirtea con alumnas frívolas como Adèle - papel realizado por la propia Kathie- que encarna la "niña mala", la juguetona y escurridiza femme fatale. Kathie no escatimará tampoco en melodrama: mientras su supuesto marido Johnny dedica su vida a coger olas en el club Waikiki ${ }^{4}$, y le engaña una y otra vez con miles de "hembritas" (Teatro 172-173) con las que demuestra su virilidad, ella, por su cuenta, se imagina encuentros amorosos con su primer amor, Víctor -encarnado por Santiago-, hombre romántico, lleno de virtudes que concuerdan con el más puro melodrama, y que Kathie rechaza por su escala social. De nuevo no es posible percibir qué es verdad, qué es mentira, ya que el personaje de Johnny que aparece vilipendiado, retratado como un ser soez y canalla -alcanzando el extremo de un suicidio literario patético-, en la escena final recibe los siguientes elogios de su mujer: "Johnny es un alma de Dios, el hombre más bueno del mundo, pero también el más inculto" (245). Este parlamento elimina la verdad "real" de todas las escenas previas, pero carece del melodrama y el patetismo que poseen las anteriores.

El melodrama, y a su vez la parodia de este género, son la fuerza que hace girar esta obra dramática, criticada por su inacción, por su falta de voluntad que se va resquebrajando cada vez que la realidad de una escena es falseada por la escena siguiente. Efraín Kristal define esta pieza teatral como "una despedida a la literatura comprometida" (Kristal 12), afirmación fácilmente justificable, ya que además de esta imagen incongruente y caricatural que dibuja en los protagonistas, otra de las características más importantes de esta obra respecto a su narrativa es la falta de referencia del contexto sociohistórico. La escena se sitúa en una buhardilla aparentemente parisina, pero posiblemente limeña; ambigüedad escénica que se comprende porque no especifica si estamos en el plano de la realidad o de la irrealidad. El medio no tiene ninguna relevancia pues todo se plantea en la imaginación, y de este modo el autor queda alejado de cualquier compromiso socio-histórico. El compromiso de Santiago esta vez se encuentra en la propia Kathie, a la que rinde laboriosamente dos horas diarias, y con la que finalmente disfruta enajenándose. La parodia descubre una autoparodia, ya que Vargas Llosa fue

${ }^{4}$ Según el crítico Álex Zisman, en su artículo "Kathie y el hipopótamo", Debate 22 (1983): 83-85, la pieza teatral se iba a llamar "Kathie y los tablistas", pero finalmente se transformó ya que la alusión era demasiado localista. De hecho, la referencia al club Waikiki no es casual. En su autobiografía, Vargas Llosa menciona este lugar y lo describe como "símbolo de pituquería; sus socios corrían las olas con tablas hawaianas, entonces un deporte carísimo" (Vargas, El pez 133). 
amanuense en 1959 para una mujer adinerada llamada Cata Podestá, de quien nace un libro, titulado Pieles negras y blancas publicado en 1960 en Lima. Sin embargo, como toda parodia, el homenaje queda explícito, sobre todo en la reveladora escena final. Santiago define a Kathie como su "cómplice" (250) y le agradece sacarle cada día de su vida mediocre. Kathie, asumiendo este juego le increpa:

KATHIE: Usted ha dicho mediocre, mediocridad. ¿No es éste un juego también demasiado mediocre?

SANTIAGO: Tal vez lo sea Kathie. Pero, al menos, no hemos perdido la imaginación, los deseos. No debemos dejar que nos quiten este juguete porque no tenemos otro (Vargas, Teatro 249).

La imaginación ya no es un arma, es un juguete con el que estos personajes tratan de intensificar, mejorar, distraer sus vidas objetivas. Es una descripción de la condición humana, cargada de pesimismo a pesar del carácter risueño que pretende conceder Vargas Llosa en las últimas escenas. El conformismo de ambos personajes, que desencadena escenas cargadas de excesos, de situaciones dramáticas infértiles, no deja lugar a dudas sobre la "insatisfacción congénita" que sufren. Sin embargo, extraemos de este retrato teatral una coincidencia con un juicio que Vargas Llosa realiza sobre la novela de Flaubert, un aspecto que le fascina por encima de todos: esta novela moderna consigue cristalizar "el reino de la mediocridad, del universo gris del hombre sin cualidades" (Vargas, Orgía 192).

Es interesante asimismo el juego de máscaras que se traduce en un articulación nominal: Kathie Kennety es una impostura decorativa que se adjudica la misma señora para tener un nombre más "extranjero, musical, cosmopolita" (Vargas, Teatro 151), y del mismo modo acuña a Santiago el de "Mark Griffin" con la intención de asemejar su irrealidad a la de su acompañante. Jonnhy es en realidad Juan, y Adèle y Víctor son los presuntos amantes que responden a la pareja mítica de Víctor Hugo y Adèle Foucher. Sin embargo, la única que no posee un nombre "verdadero" es Kathie, ser irreal hasta el final, pues es quien toma la decisión original de jugar premeditadamente a este pasatiempo de las mentiras. El lenguaje será el eje fundamental de esta pieza, ya que desde el principio se expone el juego que Priscilla Meléndez describe del siguiente modo en su artículo "Transcripción y transgresión: ironía y ficción en Kathie y el hipopótamo de Vargas Llosa": 
Vargas Llosa pone de manifiesto no solo la fragilidad de unos códigos genéricos donde la narración y la acción se funden y se confunden, sino las múltiples máscaras que asume la comunicación lingüística y dramática a través del uso de la metáfora, el juego con el concepto de traducción y la profunda ironía que revela cada una de sus fórmulas (35).

El carácter metateatral -teatro dentro del teatro- hace que los protagonistas tengan conciencia de su carácter ficcional, por lo que ellos tienen la posibilidad de aderezar cada escena con las dosis de truculencia que crean conveniente para persuadir al espectador. Vargas Llosa entrega las herramientas que desvelan la naturaleza impostora de la retórica, gracias a la cual lo espontáneo, natural -conducido por Kathie- debe pasar obligatoriamente por un filtro estético estilizado, dirigido por Santiago:

En Kathie, la contraposición entre un lenguaje absurdamente prosaico y uno irrisoriamente poético no solo desenmascara su interdependencia sino que parodia la insuficiencia de ambos creando un ciclo infinito e intrascendente. Irónicamente, en este mundo de la buhardilla parisina la acción, o más bien, la infinita recreación de la acción, aparece subordinada al lenguaje (Meléndez 35).

Podríamos advertir sin embargo cómo, de alguna forma, la autoridad del lenguaje escrito, es decir, el soporte textual que acaba siendo finalmente el oficial, posee una superioridad sobre el de Kathie. La señorita de Tacna y Kathie se expresan con libertad, pero siempre bajo la batuta de un ente masculino: Mamaé da voz a la fantasía inventiva de Belisario, Kathie se acopla a las órdenes de Santiago, que corrige su narración oral. Sin embargo, a esta altura hay que hacer un inciso e indicar que los parlamentos de los personajes femeninos no son una segunda oralidad, sino una "literalización" de una forma estética distinta. Es decir, como en La tía Julia, lo que "a fin de cuentas se opone y confronta no es la segunda oralidad y la escritura, sino dos formas de estéticas "literarias"” (Morales 57). Las mujeres son el espejo del álter ego vargasllosiano, la otredad femenina, que se materializa en lo incontrolable de la verborrea de Kathie, en la oralidad espontánea de la anciana tía abuela, y más adelante en el misterio encerrado en la "figura inmóvil" de la Chunga.

La Chunga es la última obra de esta trilogía, y la más compleja y arriesgada en su creación espectacular. En este metateatro nos encontramos de nuevo 
con varios niveles diegéticos sobre el escenario, pero el objetivo temático de Vargas Llosa está más claro:

Los temas que la obra desarrolla o roza, a través de esta historia, no deberían prestarse a confusión: el amor, el deseo, los tabúes, la relación entre el hombre y la mujer, los usos y costumbres de un cierto medio, la condición femenina en una sociedad primitiva y machista, y la manera como esos factores objetivos se reflejan en el ámbito de la fantasía (Vargas, Teatro 258).

La condición femenina viene representada una vez más por una clara polarización: la Chunga, carácter fiero e indomable con apariencia masculina que rescata Vargas Llosa de las ruinas de la Casa Verde, dueña de un bar donde los Inconquistables deambulan cada día ahogando sus penas, embriagándose; y Meche, la belleza personificada, dulce, femenina, atrayente, pero también sumisa ante las órdenes de Josefino, su amante y futuro cafiche. La pieza comienza con un enigma con nombre de mujer, como el de la Musa, que desconcierta a los cuatro amigotes que cada día vaguean en la tasca de la Chunga: durante una noche en que las apuestas de los Inconquistables rebasan el caudal de Josefino, este decide ofrecer a la Chunga su amante -su presa, Meche- por tres mil soles, a cambio de ceder una noche a la entera disposición de la tabernera. Tras ese encuentro, Meche desaparece sin dejar rastro, y los cuatro Inconquistables fabulan individualmente lo que aconteció en ese cuartillo secreto.

Esta pieza resulta muy atrevida en la fecha de su estreno, 1984, pues utiliza en sus parlamentos un lenguaje extremadamente vulgar para la época y pone sobre escena imágenes eróticas que causan escándalo. Las fantasías individuales de José, Lituma, Mono y Josefino poseen diversos ingredientes de la sexualidad más depravada: sadomasoquismo, felaciones forzadas, voyeurismo, escenas que hieren la sensibilidad del espectador al ser materializadas en la escena, con la excepción de una historia romántica que protagoniza Lituma, idealizando a la dama como en una novela de caballería. Impacta también al público de los ochenta una escena erótica homosexual en la que las dos mujeres se besan furtivamente, dejando al espectador como voyeur de lo que fueron fantasías o realidades. Jamás se resolverá el misterio.

El motor que mueve esta obra, que podría denominarse contemplativa por el ensimismamiento de todos los actores en sus imaginaciones libidinosas, es el silencio que mantiene la Chunga ante lo acontecido, y por ende, la ausencia de Meche, que conquista la mente de los Inconquistables con su aura invisible. 
En su enfrentamiento con la otredad femenina que no pueden controlar, se desgarra una violencia íntima radical. En la obra narrativa de Vargas Llosa, este silencio inmanente al ser femenino es reiterativo:

... se establece una oposición bastante acusada entre lo masculino y lo femenino como sinónimos de comunicación opuesto al silencio... los que tienen el poder controlan la comunicación... El hombre machista relega a la mujer al silencio porque se siente permanentemente amenazado, en el fondo lo que teme es su palabra (Watnicki 330-331).

Rosa Boldori aclara que en la obra de Vargas Llosa el hombre actúa "por temor a ser avasallado por ese sentido de la realidad que la mujer posee, y que significa para el hombre, la posibilidad de enfrentarse con la exacta dimensión de su debilidad y sus fracasos" (38). Josefino, el cafiche del grupo, el jefe de los Inconquistables, somete a la Chunga en su imaginación a una felación para sobrepasar el miedo que ésta le provoca a través su silencio objetivo. Necesita transgredir, quebrantar esa fortaleza que le arrastra hacia una vulnerabilidad: "la violencia implica miedo, combinado aquí con una ancestral violencia a la mujer-madre, matriz, posibilidad de fructificar-lejano resabio del inconsciente colectivo de sociedades matriarcales primordiales" (Boldori 38). Las relaciones de género en la sociedad colonial fueron víctimas de una ambiente viciado por la avidez de poder y de riqueza que identifica a los nuevos habitantes, personajes educados en la guerra, familiarizados con la dominación:

A lo largo del proceso de conquista abundaron los casos de encuentros eventuales entre los 'hombres de armas' y las mujeres indígenas comuneras. Estas situaciones, que se prolongaron luego de la consolidación del régimen colonial, además de desestabilizar las pautas de emparejamiento de los miembros del ayllu, presentaron un alto grado de violencia. Las crónicas de la época están llenas de alusiones a este tipo de hechos (Mannarelli 66).

Ciertos resabios de este período perviven entre las páginas de La casa verde, y vuelven como fantasmas al teatro para denunciar esta violencia, que no es exclusiva en Josefino, puesto que excepto Lituma, el resto de los Inconquistables agreden el cuerpo femenino, sea a través de la delectación voyeurista donde las mujeres se degradan en sus diálogos a la condición de "esclavas" o "putas", sea a través de la confesión del estupro del Mono. Esta transgresión, tanto de la belleza de Meche como de la enigmática Chunga, sin 
embargo, no contiene ningún efecto fecundante. Como afirmaba el Marqués de Sade, el lenguaje es excesivo, pero nunca desborda en la realidad. Bataille, al ejercer la crítica sobre el lenguaje de Sade afirmaba que este correspondía al de una víctima amedrentada:

Es solo un exceso, un exceso vertiginoso, pero es la cima excesiva de lo que somos. De esta cima no podemos apartarnos sin apartarnos de nosotros mismos. Por no acercarnos a dicha cima, o no esforzarnos por trepar al menos sus laderas, vivimos como sombras amedrentadas $-\mathrm{y}$ ante quienes temblamos es ante nosotros mismos (El erotismo 198).

Meche y la Chunga poco tienen en común: la primera entrega su vida al culto de la belleza y al sometimiento a un hombre, la última se defiende de los hombres con la represión de todo deseo, de cualquier atisbo de humanidad, hasta el punto de utilizar ella misma a la ingenua Meche. No obstante, ambas cumplen la función de la mujer en la obra vargasllosiana: son un "texto plural inapropiable" (Béjar 246) ${ }^{5}$ al que los Inconquistables transgreden, mancillan en su imaginación, pero inalcanzables, escurridizas, inaprensibles en su realidad, como la solitaria que representa para Vargas Llosa la vocación literaria: corroe cada parte del cuerpo pero se halla escondida en lo más interno del ser humano.

Alberto Ísola, actor de la compañía peruana que estrenó esta pieza, define brillantemente el papel de la Chunga, cuya asonancia con la Musa no debe ser casual: "le hizo recordar a esas diosas de ciertas tribus que representan la figura femenina, central y autosuficiente; aquella que causa temor y terror al mismo tiempo que atracción, ya que es diosa tanto de la muerte como de la reproducción" (Fort 69).

"Chunga con Meche/Meche con Chunga" (Vargas, Teatro 275) -cantan los Inconquistables- son caras de una misma moneda. La voluntad de ambas se traduce en la absoluta entrega de Meche, nacida de su inocencia, y en la defensa a ultranza de la dignidad de la Chunga, aleccionada ya tras las circunstancias que le ha tocado vivir; "porque no quieres ver la vida como es. Lo monstruoso es la vida. No yo" (346) advierte la Chunga a Meche. Ellen Watnicki Echevarría define esta relación con la imagen especular femenina

${ }^{5}$ Este autor distingue la función "abierta y plural" de la mujer como metáfora del texto en las obras ¿Quién mató a Palomino Molero? (1986) y Elogio de la madrastra (1988), y de la postura machista de la mujer en La señorita de Tacna o Kathie y el hipopótamo, donde la materia ficcional del escribidor (autor) sirve de arreglo o perfección al material oral de la mujer. 
como una relación de opresor/oprimido en la que la relación macho-hembra se asimila a la del criollo y el indio:

Para el indio la relación hombre-mujer se puede dar en machohembra en un ambiente natural: posesión fecundante, agricultura y amor, tierra y mujer...Con la conquista surge la perversión de esa relación: la relación natural se hace promiscuidad en el mestizo. Se da la oscilación entre la vida natural y los desbarajustes socioculturales que trae consigo la relación opresor y oprimido, que se deja sentir en la relación hombre-mujer (Cit. en Watnicki 256)

Con el fin de ejemplificar esta relación, analizamos el curioso epíteto de mujeres "sin edad" que Vargas Llosa adjudica a varias presencias femeninas de estrato social bajo a lo largo de su obra. Obsérvese la comparación entre la descripción de la Chunga: "una mujer espigada y sin edad, de expresión dura, de piel lisa y tirante, huesos firmes y ademanes enérgicos, que mira a la gente sin pestañear" (Teatro 264. La cursiva es mía); y la descripción de una india en Lituma en los Andes: "Era pequeñita y sin edad, de huesos frágiles, como de pájaro, y desaparecía bajo las numerosas polleras y el sombrero rotoso, medio caído. Pero en la cara y en sus ojitos arrugados había algo irrompible" (14, la cursiva es mía). Coinciden en la incertidumbre de la edad y en la mirada helada, impertérrita, atributos que parecen remitir a un personaje mítico. El autor dota a estas mujeres de un atributo legendario muy particular, similar al de la creación poética, que posee nombre de mujer. Finalmente, las mujeres constituyen un reverso de la literatura, transgredida por el autor peruano en múltiples experimentaciones, vocación literaria obsesiva, corroyente, pero por su misma condición, omnipotente. Al igual que la literatura, las mujeres son:

Los verdaderos guardianes del "templo", las que regulan el orden social representado en la diéresis, las que lo hacen trizas también si es necesario en última instancia, las que fecundan su eventual renacer, las que perpetúan las memorias del pasado. Todopoderosas, vigilantes, frágiles, conmovedoras, temibles y seductoras, hilan y cortan los vínculos que unen o separan a los personajes masculinos, hacen o deshacen el tejido social representado desde lugares sumamente humildes en el argumento de las ficciones (Gómez 311).

Cabe aludir brevemente a una evolución literaria evidenciada por diversos críticos en el aumento de hondura y tono psicológico que cede a los papeles 
femeninos surgidos a partir de la década de los noventa. La mujer de tinta y papel adquiere personalidad y garra en la dramaturgia de esta época. En El loco de los balcones (1993), Ojos bonitos, cuadros feos (1996) y Al pie del Támesis (2008), las mujeres poseen una fuerza arrolladora que no se interrumpe ante la autoridad masculina, aunque siguen siendo fantasmas de la mente de un narrador generador varón. Esta vez, sin embargo, el freno lo impondrán ellas mismas, ya que de alguna forma se sienten "raras" al no encajar en el patrón machista y bien recurren al matrimonio por conveniencia para escapar del cobijo paterno, como Ileana (El loco de los balcones), bien acaban suicidándose al darse cuenta de su sensibilidad como artista, y no como ama de hogar, como Alicia (Ojos bonitos, cuadros feos) $)^{6}$. No es menos llamativo el protagonismo que cede Vargas Llosa a las dos narradoras universales de la historia de la literatura: Penélope y Sherezade serán las encargadas de transportar al espectador al mundo de la ilusión con Odiseo y Penélope (2006) y Las mil noches y una noche (2009).

En el campo de la narrativa, críticos como Giulia De Sarlo o Stephen Henighan consideran La fiesta del Chivo (2000), El paraíso en la otra esquina (2003) y Travesuras de la niña mala (2006) como verdaderos avances en la tipología de la mujer, con numerosas salvedades que no podremos recuperar en este artículo por cuestión de espacio. No obstante, quisiera llamar la atención sobre la reciente generalización de una interpretación metaliteraria de la penúltima obra de Vargas Llosa: Travesuras de la niña mala ${ }^{7}$, en la que la "niña mala" es vista como metáfora de la vocación literaria. La mujer, como la literatura, continuará siendo "un asunto misterioso, desde luego, cercado de incertidumbre y subjetividad" (Vargas, Cartas 9) y, como hemos comprobado a lo largo de este paseo por el teatro, posee una fuerza soterrada, pero potente, llena de afirmación de vida, afín a la literatura de Vargas Llosa, que recorre y pervierte cada subgénero, que ensaya cada estética, camuflándose cada vez con un ropaje distinto, como "la niña mala", como la solitaria.

Como una prostituta, ubicada en los intersticios de los cuerpos sociales [...], la literatura hispanoamericana contemporánea, de modo abierto y

${ }^{6}$ Desarrollo este tema con más detenimiento en "La Lima que viene y va: últimas obras teatrales de Mario Vargas Llosa". Revista Cultura Turia 97-98: 311-330.

${ }^{7}$ Aparte de los mencionados tenemos otros ejemplos, como el crítico Efraín Kristal, José Morales Saravia, o Giovanna Pollarolo: "La niña mala como alegoría de una vocación literaria", Perú en el espejo de Vargas Llosa. México: Universidad de las Américas Puebla, 2008. 71-82. 
no ya clandestino, se va con los dos términos de la oposición, se va con los golpistas, así como con los golpeados; incluye a los dominantes, así como a los dominados; abraza la norma, así como a su réplica polémica en un solo abrazo fecundo y críticamente gozoso. [...] Esta zona oculta e inestable (a menos que uno se viva como un dogmático irredento) está hecha de la transfugacidad y transferencia de nuestros sentimientos y deseos, los que, incluso, nos llevan desapercibidamente a adoptar maneras, hábitos e ideas de quienes repudiamos o hasta consideramos nuestros enemigos (Hovzen 106).

\section{BIBLIOGRAFÍA}

Barchino, Matías. “La poética del escribidor”. Revista Cultura Turia 97-98 (2010): 219-232.

Bataille, Georges. Historia del ojo. Barcelona: Tusquets, 1978.

El erotismo. Barcelona: Tusquets, 2002.

Béjar, Eduardo. “La fuga erótica de Mario Vargas Llosa”. Symposium 46.4 (1992-1993): 243-256.

Boldori, Rosa. Vargas Llosa: un narrador y sus demonios. Buenos Aires: Fernando García Cambeiro, 1974.

Cueto Alonso y Úrsula Freundt-Thurne. Vargas Llosa: La vida en movimiento. Lima: Universidad peruana de ciencias aplicadas, 2003.

De Sarlo, Giulia. "Entre masculino y femenino. La narrativa de Vargas Llosa a la vuelta del milenio". Libros \& Artes. Revista de cultura de la Biblioteca Nacional del Perú. IX/ 44-45 (2010): 8-11.

Edwards, Jorge. "Vargas Llosa. Los años de París". El autor y su obra: Mario Vargas Llosa. Mario Vargas Llosa, Rafael Conte et al. Madrid: Universidad Complutense de Madrid, Cursos de verano (1989. El Escorial), 1990.

Fort, Maria Amelia. “¡La Chunga!”. Caretas 880 (1985): 68-69.

Gómez Vidal, Elvira. "Poética de la figura femenina en la obra de Vargas Llosa". Mario Vargas Llosa: perspectivas críticas. Pol Popovik y Fidel Chávez Pérez. México: Tecnológico de Monterrey, 2010. 281-314.

Guichot Muñoz, Elena. "La Lima que viene y va: últimas obras teatrales de Mario Vargas Llosa”. Revista Cultura Turia 97-98 (2010): 311-330.

Henighan, Stephen. "Lo femenino como nostalgia en La fiesta del chivo, El paraíso en la otra esquina y Travesuras de la niña mala". Perú en el espejo de Vargas Llosa. Javier Vargas de Luna y Emilia Deffis. México: Universidad de las Américas Puebla, 2008. 55-70.

Hozven, Roberto. "Relaciones equívocas: el prostíbulo y la literatura hispanoamericana actual". Revista Chilena de Literatura 64 (2004): 103-107. http://www.revistaliteratura. uchile.cl/index.php/RCL/article/viewArticle/1592/1474

Kristal, Efraín. "Prólogo". Obras completas de Mario Vargas Llosa. Vol. III. Barcelona: Galaxia Gutenberg, Círculo de Lectores, 2005. 
Luna Escudero Alie, María Elvira. "La señorita de Tacna (1981), de Mario Vargas Llosa o la poética de la nostalgia”. Konvergencias Literatura III/10 (2009): 86-92.

Mannarelli, María Emma. "Las relaciones de género en la sociedad colonial peruana. Ilegitimidad y jerarquías sociales". Feijóo, María del Carmen (Comp.) Mujer y sociedad en América Latina. Buenos Aires: CLACSO, 1991. 63-107.

Meléndez, Priscilla. "Transcripción y transgresión: ironía y ficción en Kathie y el hipopótamo, de Vargas Llosa”. Revista canadiense de estudios hispánicos 15/ 1 (1990): 35-47.

Morales Saravia, José. Exilios y desexilios de la comicidad. Estudios sobre la novelística de Mario Vargas Llosa. Lima: Editorial San Marcos, 2009.

Oviedo, José Miguel. "De la tía Julia a La señorita de Tacna”. Quimera 4 (1981): 23-26.

Polo García, Victorino (ed.). Diálogo del conocimiento: encuentro con Mario Vargas Llosa. Murcia: Cajamurcia, 1994.

Rojas Benavente, Lady. "La invención teatral de Mamaé y del escritor Belisario en La señorita de Tacna (1981), de Mario Vargas Llosa”. Perú en el espejo de Vargas Llosa. México: Universidad de las Américas Puebla, 2008. Javier Vargas de Luna y Emilia Deffis. 145-156.

Vargas Llosa, Mario. Conversación en La Catedral. Vol. II. Barcelona: Seix Barral, 1969.

La orgía perpetua: Flaubert y Madame Bovary. Barcelona: Bruguera, 1985 (edición original: Seix Barral, 1975).

La tía Julia y el escribidor. Barcelona: Seix Barral, 1977.

Semana del autor: Mario Vargas Llosa. Madrid: Ediciones de Cultura Hispánica, Instituto de Cooperación Iberoamericana, 1985.

Contra viento y marea (1972-1983). Vol. II. Barcelona: Seix Barral, 1986.

Lituma en los Andes. Barcelona: Planeta, 1993.

El pez en el agua. 1993. Madrid: Alfaguara, 2005.

Cartas a un joven novelista. Barcelona: Ariel, 1997.

Obra reunida. Teatro. Madrid: Alfaguara, 2001.

Entrevistas escogidas. Lima: Fondo editorial de Cultura Peruana, 2004.

Odiseo y Penélope. Madrid: Galaxia Gutenberg, 2006.

Diccionario del amante de América Latina. Barcelona: Paidós, 2006.

Watnicki Echevarría, Ellen. La significación de la mujer en la narrativa de Mario Vargas Llosa. Tesis Doctoral. Madrid: Universidad Complutense de Madrid, 1993. 